\title{
HUBUNGAN PENGETAHUAN DENGAN MINAT IBU HAMIL TM II DAN III TERHADAP PRENATAL GENTLE YOGA
}

\author{
Aris Noviani $^{1)}$, Siskana Dewi Rosita ${ }^{2)}$ \\ ${ }^{1}$ Prodi D3 Kebidanan, STIKes Mitra Husada Karanganyar \\ ${ }^{2}$ Prodi D3 Kebidanan, STIKes Mitra Husada Karanganyar \\ Email: arisnoviani@gmail.com
}

\begin{abstract}
ABSTRAK
Kehamilan merupakan sebuah proses alamiah pada manusia tanpa kondisi yang patologis, ibu hamil dapat melakukan prenatal gentle yoga untuk menjaga kesehatan selama kehamilan. Banyaknya promosi tentang prenatal gentle yoga tidak serta langsung menarik minat para ibu hamil padahal banyak manfaat yang bisa didapatkan. Penelitian ini bertujuan untuk menganalisa hubungan pengetahuan dengan minat ibu hamil trimester II dan III terhadap prenatal gentle yoga di Desa Madegondo, Kecamatan Grogol, Kabupaten Sukoharjo. Jenis penelitian ini adalah Analitik Correlational dengan rancangan Cross Sectional. Populasi penelitian ini adalah seluruh ibu hamil trimester II dan III di Desa Madegondo Kecamatan Grogol Kabupaten Sukoharjo sejumlah 30 ibu hamil. Sampel penelitian sejumlah 30 ibu hamil, diambil secara Proporsional Random Sampling. Variabel independent penelitian ini adalah pengetahuan ibu hamil tentang prenatal gentle yoga dan variabel dependent penelitian ini adalah minat ibu hamil terhadapa prenatal gentle yoga. Instrument penelitiannya menggunakan kuesioner. Pengolahan data menggunakan Editing, Coding, Scoring, Tabulating dan Uji statistik Spearman Rank. Hasil penelitian menunjukkan pengetahuan ibu hamil tentang senam yoga didapatkan 20 responden berpengetahuan cukup $(66,7 \%)$, sedangkan minat ibu hamil dalam penerapan senam yoga didapatkan 19 responden minat sedang (63,3\%). Uji statistik Spearman Rank menunjukkan bahwa $\rho$ value $=0,000<\alpha(0,05)$, sehingga $\mathrm{H}_{1}$ diterima. Kesimpulan penelitian ini ada hubungan pengetahuan dengan minat ibu hamil TM II dan III terhadap prenatal gentle yoga di Desa Madegondo Kecamatan Grogol Kabupaten Sukoharjo.
\end{abstract}

Kata Kunci: Pengetahuan, Minat, Ibu Hamil, Prenatal Gentle Yoga

\begin{abstract}
Pregnancy is a natural process in humans without pathological conditions, pregnant women can do prenatal gentle yoga to maintain health during pregnancy. Massive promotions about prenatal gentle yoga do not straightaway attract the interest of pregnant women even though there are many benefits that can be obtained. This study aims to analyze the relationship between knowledge and the interest of pregnant women in the second and third trimesters of prenatal gentle yoga in Madegondo Village, Grogol District, Sukoharjo Regency. This type of research is Correlational Analytical with Cross Sectional design. The population of this study were all pregnant women in the second and third trimesters in Madegondo Village, Grogol District, Sukoharjo Regency, with a total of 30 pregnant women. The research sample was 30 pregnant women, taken by Proportional Random Sampling. The independent variable of this study was the knowledge of pregnant women about prenatal gentle yoga and the dependent variable of this study was the interest of pregnant women in prenatal gentle yoga. The research instrument used a questionnaire. Data processing used Editing, Coding, Scoring, Tabulating and Spearman Rank statistical tests. The results showed that the knowledge of pregnant women about yoga exercise obtained 20 respondents with sufficient knowledge (66.7\%), while the interest of pregnant women in the application of yoga exercise obtained 19 respondents with moderate interest (63.3\%). Spearman Rank statistical test showed that value $=0.000<(0.05)$, so $\mathrm{Hl}$ is accepted. This study found that there is a relationship between knowledge and the interest of pregnant women in TM II and III towards prenatal gentle yoga in the village of Madegondo, Grogol District, Sukoharjo Regency.
\end{abstract}

Keywords: Knowledge, Interests, Pregnant Women, Prenatal Gentle Yoga 


\section{PENDAHULUAN}

Kehamilan merupakan sebuah proses alamiah pada manusia, dan bukan merupakan proses patologis, kecuali keadaan-keadaan tertentu. (Prawirohardjo, 2011).

Berdasarakan data WHO pada tahun 2014 yaitu Angka Kematian Ibu (AKI) di dunia sebanyak 289.000 jiwa. AKI yang tinggi dimiliki oleh Negara berkembang yaitu negara di Afrika Sub-Saharan dengan 179.000 jiwa, negara di Asia Selatan dengan 69.000 jiwa, serta negara di Asia Tenggara dengan 16.000 jiwa. AKI yang terjadi di negara-negara Asia Tenggara yaitu negara, negara Vietnam dengan 49 per 100.000 kelahiran hidup, negara Thailand dengan26 per 100.000 kelahiran hidup, negara Brunei dengan 27 per100.000 kelahiran hidup, dan di negara Malaysia dengan 29 per 100.000 kelahiran hidup dan Indonesia dengan 190 per 100.000 kelahiran hidup (WHO, 2014).

Penurunan Angka Kematian Ibu di Indonesia masih belum cukup signifikan yakni menurun 59 hal ini dibuktikan dari data Survei Penduduk Antar Sensus (SUPAS) 2015 yaitu 305 kematian ibu per 100.000 kelahiran hidup yang sebelumnya pada hasil Survei Demografi Kesehatan Indonesia (SDKI) tahun 2012 dengan angka 359 kematian ibu per 100.000 kelahiran hidup (Kemenkes RI, 2019).

Jumlah kasus kematian ibu yang terjadi di Provinsi Jawa Tengah pada tahun 2016 sebanyak 602 kasus, dibandingkan jumlah kasus kematian ibu pada tahun 2015 yang berjumlah sebanyak 619 kasus, pada tahun 2016 kasus kematian ibu mengalami penurunan. Terjadinya penurunan angka kematian ibu tersebut, maka angka kematian ibu di Provinsi Jawa Tengah juga mengalami penurunan pada tahun 2015 dari 111,16 per 100.000 kelahiran hidup pada tahun 2016 menjadi 109, 65 per 100.000 kelahiran hidup (Dinkes Provinsi Jateng, 2017)

Penyumbang dari tingginya angka Kematian ibu di Indoneia salah satunya pada kelompok kehamilan risiko tinggi. Hal ini dibuktikan bahwa kematian akibat kehamilan resiko tinggi pada tahun 2010 adalah sekitar 34\%. (WHO, 2012). Penyebab kematian ibu akibat gangguan hipertensi sebanyak 33,07\%, perdarahan obstetrik $27.03 \%$, komplikasi non obstetrik $15.7 \%$, komplikasi obstetrik lainnya
$12.04 \%$, infeksi pada kehamilan $6.06 \%$ dan penyebab lainnya $4.81 \%$ (Kemenkes, 2019).

Namun, hal ini tidak dapat menjadi tolak ukur akan kejadian tersebut, karena komplikasi persalinan dapat juga terjadi pada ibu hamil yang tidak mempunyai faktor-faktor risiko. Oleh sebab itu, bidan sebagai petugas pelayanan kesehatan yang memiliki hubungan langsung dengan ibu hamil dalam pemberian asuhan atau perawatan kehamilan (antenatal care) berperan penting untuk mengelola pencegahan risiko melalui skrinning sehingga dapat menentukan tingkat risiko sesuai dengan tingkat kegawatan dari faktor risiko tersebut.

Mengingat banyaknya kondisi yang dapat dikaitkan dengan kehamilan risiko tinggi, maka setiap Ibu, sebelum hamil, dengan atau tanpa kondisi medis sebelumnya, perlu menemui tenaga kesehatan terdekat untuk mempersiapkan kehamilan dengan baik agar kondisi berpotensi menganggu kehamilan dapat dideteksi dan diatasi secepatnya.

Sebagian besar penyebab utama kesakitan dan kematian ibu tersebut sebenarnya dapat dicegah melalui upaya pencegahan yang efektif. Asuhan kesehatan ibu selama dua dasawarsa terakhir terfokus kepada : Keluarga Berencana untuk lebih menyejahterakan anggota masyarakat. Asuhan Neonatal terfokus untuk memantau perkembangan kehamilan mengenai gejala dan tanda bahaya, menyediakan persalinan dan kesediaan menghadapi komplikasi. Asuhan Pasca Keguguran untuk penatalaksaan gawat darurat keguguran dan komplikasinya serta tanggap terhadap kebutuhan pelayanan kesehatan reproduksi lainnya.

\section{METODE}

Jenis penelitian ini adalah penelitian yang bersifat Analitik Correlational. Analitik Correlational adalah penelitian yang bertujuan untuk menentukan hipotesis yang ada, Hal ini dilakukan untuk melihat hubungan antara satu variabel dengan variabel yang lain (Soekidjo Notoatmodjo, 2010). Penelitian ini menilai hubungan pengetahuan dengan minat ibu hamil dalam penerapan prenatal gentle yoga.

Penelitian ini dilaksanakan di Desa Madegondo Kecamatan Grogol Kabupaten Sukoharjo pada bulan April 2021.

Pada penelitian ini populasinya pengambilan data untuk bulan Maret adalah 
seluruh ibu hamil trimester II dan trimester III yang berada di Desa Madegondo Kecamatan Grogol Kabupaten Sukoharjo sejumlah 30 ibu hamil.

Tehnik sampling yang di gunakan dalam penelitian ini adalah "Total Sampling" dimana semua populasi dijadikan sampel (Sugiyono, 2007). Dengan jumlah 30 Ibu hamil

Instrumen yang digunakan adalah lembar pertanyaan (kuesioner) yang harus diisi oleh responden. Kuesioner yang digunakan dalam penelitian ini adalah kuesioner tertutup. Kuesioner tertutup adalah kuesioner yang sudah

Table 1

Distribusi responden berdasarkan umur

\begin{tabular}{clcc}
\hline No & Umur & Jumlah & Persentase \\
\hline 1 & $20-30$ tahun & 15 & 50 \\
2 & $31-40$ tahun & 15 & 50 \\
3 & $>40$ tahun & - & - \\
& Jumlah & 30 & 100 \\
\hline
\end{tabular}

Berdasarkan tabel diatas maka dapat disimpulkan bahwa persentase umur responden sama yaitu 20-30 tahun sebanyak 15 ibu hamil disediakan jawabannya sehingga responden tinggal memilih (Arikunto, 2006).

Uji yang digunakan adalah uji Spearmen Rank. Tehnik analisa data dengan editing, coding, scoring dan tabulating.

\section{HASIL}

\section{A. Data umum}

\section{Berdasarkan umur}

Distribusi umur responden penelitian sebagai berikut :

(50\%) dan 31-40 tahun sebanyak 15 ibu hamil $(50 \%)$.

\section{Berdasarkan Pendidikan}

Distribusi pendidikan responden penelitian sebagai berikut :

Table 2

Distribusi responden berdasarkan pendidikan

\begin{tabular}{|c|c|c|c|}
\hline No & Pendidikan & Jumlah & Persentase \\
\hline 1 & SD/MI & 1 & 3,3 \\
\hline 2 & SMP/MTS & 2 & 6,7 \\
\hline 3 & SMA/SMK/MA & 7 & 23,3 \\
\hline \multirow[t]{2}{*}{4} & Perguruan Tinggi & 20 & 66,7 \\
\hline & Jumlah & 30 & 100 \\
\hline
\end{tabular}

Table 3

Distribusi responden berdasarkan pekerjaan

\begin{tabular}{llcc}
\hline No & Pekerjaan & Jumlah & Persentase \\
\hline 1 & IRT & 14 & 46,7 \\
2 & SWASTA & 11 & 36,7 \\
3 & PNS & 5 & 16,7 \\
& Jumlah & 30 & 100
\end{tabular}

Berdasarkan tabel diatas maka dapat disimpulkan bahwa mayoritas pekerjaan responden yaitu IRT/Ibu rumah tangga sebanyak 14 ibu hamil $(46,7 \%)$.
4. Berdasarkan usia kehamilan

Distribusi Usia kehamilan responden penelitian sebagai berikut : 
Table 4

Distribusi responden berdasarkan usia kehamilan

\begin{tabular}{llcc}
\hline No & UK & Jumlah & Persentase \\
\hline 1 & $4-6$ bulan & 15 & 50 \\
2 & $7-9$ bulan & 15 & 50 \\
& Jumlah & 30 & 100 \\
\hline
\end{tabular}

Berdasarkan tabel diatas maka dapat disimpulkan bahwa mayoritas usia kehamilan responden yaitu sama 4-6 bulan dan 7-9 bulan sebanyak masing-masing 15 ibu hamil (50\%).

\section{Berdasarkan informasi \\ Distribusi informasi responden penelitian sebagai berikut :}

Table 5

Distribusi responden berdasarkan informasi

\begin{tabular}{llcc}
\hline No & Informasi & Jumlah & Persentase \\
\hline 1 & Pernah & 6 & 20 \\
2 & Tidak pernah & 24 & 80 \\
& Jumlah & 30 & 100 \\
\hline
\end{tabular}

Berdasarkan tabel diatas maka dapat disimpulkan bahwa mayoritas informasi yang didapat responden yaitu tidak pernah mendapatkan informasi sebanyak masingmasing 24 ibu hamil (80\%).

\section{Berdasarkan sumber informasi}

Distribusi sumber informasi responden penelitian sebagai berikut :

Table 6

Distribusi responden berdasarkan sumber informasi

\begin{tabular}{clcc}
\hline No & \multicolumn{1}{c}{ Sumber Informasi } & Jumlah & Persentase \\
\hline 1 & Tenaga Kesehatan & 11 & 36,7 \\
2 & Media cetak & 3 & 10 \\
3 & Media Elektronik & 10 & 33,3 \\
4 & Teman, Saudara, Kader & 6 & 20 \\
& Jumlah & 30 & 100 \\
\hline
\end{tabular}

Berdasarkan tabel diatas maka dapat disimpulkan bahwa mayoritas sumber informasi yang didapat responden yaitu dari sumber informasi sebanyak masing-masing $10 \mathrm{ibu}$ hamil $(33,3 \%)$.

\section{B. Data khusus}

\section{Pengetahuan Ibu Hamil tentang Prenatal Gentle Yoga}

Distribusi pengetahuan responden penelitian sebagai berikut :

Table 7

Distribusi responden berdasarkan sumber informasi

\begin{tabular}{llcc}
\hline No & Pengetahuan & Jumlah & Persentase \\
\hline 1 & Baik & 10 & 33,3 \\
2 & Cukup & 20 & 66,7 \\
3 & Kurang & 0 & 0 \\
& Jumlah & 30 & 100
\end{tabular}

Berdasarkan tabel diatas maka dapat disimpulkan bahwa mayoritas pengetahuan responden yaitu dari sumber informasi sebanyak masing-masing 20 ibu hamil (66,7\%).
2. Minat Ibu Hamil tentang Prenatal Gentle Yoga

Distribusi pengetahuan responden penelitian sebagai berikut :

Table 8

Distribusi responden berdasarkan sumber informasi

\begin{tabular}{lccc}
\hline No & Minat & Jumlah & Persentase \\
\hline 1 & Tinggi & 10 & 33,3 \\
2 & Sedang & 19 & 63,3 \\
3 & Rendah & 1 & 3,3 \\
& Jumlah & 30 & 100 \\
\hline
\end{tabular}


Berdasarkan tabel diatas maka dapat disimpulkan bahwa mayoritas minat responden yaitu sedang sebanyak masing-masing $19 \mathrm{ibu}$ hamil $(63,3 \%)$.

\section{Hubungan pengetahuan dan minat ibu hamil tentang prenatal gentle yoga}

Distribusi hubungan pengetahuan dan minat responden penelitian sebagai berikut :

Table 9

Distribusi responden berdasarkan hubungan pengetahuan dan minat

\begin{tabular}{llrlrrrrr}
\hline $\begin{array}{c}\text { Pengetahu } \\
\text { an }\end{array}$ & & \multicolumn{1}{c}{ Tinggi } & \multicolumn{2}{c}{$\begin{array}{c}\text { Minat } \\
\text { Sedang }\end{array}$} & \multicolumn{2}{c}{ Rendah } & & Jumlah \\
\hline & $\Sigma$ & $(\boldsymbol{\%})$ & $\Sigma$ & $(\boldsymbol{\%})$ & $\Sigma$ & $(\boldsymbol{\%})$ & $\Sigma$ & $(\boldsymbol{\%})$ \\
Baik & 8 & 26,6 & 2 & 6,6 & 0 & 0 & 10 & 33,3 \\
Cukup & 2 & 6,6 & 17 & 56,6 & 1 & 3,3 & 20 & 66,6 \\
Kurang & 0 & 0,0 & 0 & 0,0 & 0 & 0,0 & 30 & 0,0 \\
Total & 10 & & 19 & & 1 & & 30 & 100,0 \\
\hline
\end{tabular}

\section{Uji Sparman Rank $\rho$ Value $=0,000<0,05$}

Berdasarkan tabel 9 menunjukkan

bahwa dari 30 responden hampir setengah responden mempunyai pengetahuan yang cukup dan minat sedang dalam penerapan senam yoga yaitu sejumlah 17 responden $(56,6 \%)$.

Setelah data diolah dengan SPSS for windows 16 dengan uji Spearman Rank menunjukkan bahwa nilai signifikasi $\rho=0,000$

\section{PEMBaHASAN}

Berdasarkan tabel 7 dapat diketahui bahwa dari 30 responden sebagian besar responden mempunyai pengetahuan cukup tentang prenatal gentle yoga yaitu 20 responden $(66,7 \%)$.

Pengetahuan tentang prenatal gentle yoga tersebut meliputi enam indikator, yaitu pengertian, manfaat, prinsip, indikasi dan kontraindikasi, persiapan dan teknik yoga dalam kehamilan. Berdasarkan hasil tabulasi data yang telah diperoleh, bahwa persentase per-indikator yaitu pengertian prenatal gentle yoga $15,8 \%$, manfaat prenatal gentle yoga $17,0 \%$, prinsip prenatal gentle yoga $17,0 \%$, Indikasi dan kontraindikasi prenatal gentle yoga16,4\%, persiapan prenatal gentle yoga $14,1 \%$ dan teknik yoga dalam kehamilan 19,5\% dari keenam indikator tersebut indikator teknik yoga dalam kehamilan memiliki prosentasi tertinggi.

Berdasarkan tabel 8 dapat diketahui bahwa dari 30 responden sebagian besar responden mempunyai minat sedang untuk menerapkan prenatal gentle yoga yaitu 19 responden $(63,3 \%)$. $<\alpha(0,05)$, sehingga $\mathrm{H}_{1}$ diterima. Hal ini menunjukkam bahwa ada hubungan pengetahuan dengan minat ibu hamil TM II dan III terhadap prenatal gentle yoga di Desa Madegondo Kecamatan Grogol Kabupaten Sukoharjo.

Indokator untuk mengukur minat ibu hamil dalam penerapan prenatal gentle yogaterdiri dari 2 parameter yaitu minat instrinsik dan minat ekstrinsik. Hasil tabulasi dari masing-masing parameter yang meliputi minat intrinsik dan minat ekstrinsik menunjukkan bahwa persentase parameter yaitu minat intrinsik sejumlah $54,1 \%$ dan minat ekstrinsik 45,8\%. Dari kedua parameter tersebut, parameter minat instrinsik memiliki prosentase tertinggi.

Berdasarkan tabel 9 menunjukkan bahwa dari 30 responden hampir setengah responden mempunyai pengetahuan yang cukup dan minat sedang dalam penerapan senam yoga yaitu sejumlah 17 responden $(56,6 \%)$.

Berdasarkan hasil analisa menggunakan uji Spearman Rank dengan bantuan SPSS for windows 16 dengan $\rho 0,05$ didapatkan bahwa $\rho$ hitung $=0,000<0,05$ maka $\mathrm{H} 1$ diterima artinya ada hubungan pengetahuan dengan minat ibu hamil terhadap prenatal gentle yoga di Desa Madegondo Kecamatan Grogol, Kabupaten Sukoharjo. Menurut peneliti pengetahuan merupakan dasar dari seseorang untuk melakukan sesuatu dan kunci dasar utama dalam menumbuhkan minat seseorang. 
Pengetahuan dapat diperoleh dari berbagai cara misalnya dengan belajar dan dari pengalaman. Untuk dapat menimbulkan ketertarikan dalam suatu hal maka seseorang membutuhkan suatu pemahaman dalam suatu hal tertentu, sehingga pengetahuan sangat berkaitan dengan minat seseorang. Responden yang masih mempunyai pengetahuan cukup sangat disarankan agar lebih meningkatkan pengetahuannya mengenai senam yoga untuk kehamilan dan dapat menerapkannya. Semakin banyak pengetahuan yang diperoleh maka akan semakin tinggi minat yang akan tumbuh pada diri seorang tersebut. Hal ini sesuai dengan teori (Rumini, 1998) yang mengatakan bahwa semakin baik pengetahuan maka akan semakin baik minat yang ditujukan pada objek tersebut, sebaliknya jika pengetahuan kurang maka akan terbentuk minat yang rendah.

Penelitian ini didukung oleh penelitian sebelumnya yaitu penelitian (Sari, 2018) dengan judul tingkat pengetahuan dan minat ibu hamil tentang prenatal yoga di Puskemas II Denpasar Selatan dengan hasil Berdasarkan hasil penelitian paling banyak ibu hamil memiliki pengetahuan baik dan minat yang sedang.

\section{SIMPULAN DAN SARAN Simpulan}

Berdasarkan hasil analisa menggunakan uji Spearman Rank dengan bantuan SPSS for windows 16 dengan $\rho 0,05$ didapatkan bahwa $\rho$ hitung $=0,000<0,05$ maka H1 diterima artinya ada hubungan pengetahuan dengan minat ibu hamil terhadap prenatal gentle yoga di Desa Madegondo Kecamatan Grogol, Kabupaten Sukoharjo.

\section{Saran}

1. Mensosialisasikan prenatal gentle yoga dengan metode, tehnik, media yang sekarang menarik perhatian para ibu hamil seperti media sosial melalui media elektronik.

2. Melibatkan para kader, keluarga dan masyarakat tentangmanfaat prenatal gentle yoga.

\section{DAFTAR PUSTAKA}

Arikunto, S. 2010. Prosedur Penelitian suatu Pendekatan Praktek. Rineka Cipta. Jakarta.
Aritonang, Irianton, 2000. Pemantauan Pertumbuhan Balita. Jakarta: Kanisius

Depkes RI. 2003. Pedoman Pelatihan Kader Kelompok Usia Lanjut Bagi Petugas Kesehatan. Jakarta : Depkes RI

Dewi arlina, dkk. 2019. Deteksi Dini Kehamilan Resiko Tinggi Bagi Kader Kesehatan. Yogyakarta: Leutika Prio

Dinkes Provinsi Jawa Tengah. 2017. Profil Kesehatan Jawa Tengah Tahun 2016. Semarang: Dinas Provinsi Jawa Tengah.

Dinkes Provinsi Jawa Timur. 2006. Panduan Pelatihan Kader Posyandu. DIPA Program Perbaikan Gizi Masyarakat.

Effendy, N. 1998. Dasar-Dasar Keperawatan Kesehatan Masyarakat. Edisi 2. Jakarta: EGC

Fadlun dan Feryanto. 2011. Asuhan Kebidanan Patologis. Jakarta: Salemba Medika.

Field, Tiffany. 2011. Complementary Therapies in Clinical Practice. Elsevier volume 17 (2011) pp 1-8

Haryati, N. 2012. Buku Acuan Nasional Pelayanan Kesehatan Maternal dan Neonatal. Jakarta: Bumi Aksara

Husin, F., 2013. Asuhan kehamilan berbasis bukti. Jakarta : Sagung Seto

Kemenkes. 2019. Strategi Penurunan AKI dan Neonatal

://www.kesmas.kemkes.go.id/portal/kont en/ rilis-berita/021517-di-rakesnas 2019 _-dirjen-kesmas-paparkan-strategipenurunan-aki-dan-neonatal

Kementrian Kesehatan RI. 2014. Pedoman Pemantauan Wilayah Setempat Kesehatan Ibu dan Anak. Jakarta.

Kusmiyati, Yuni. 2011. Perawatan Ibu Hamil (Asuhan Ibu Hamil). Cetakan Ke Enam. EGC.

Latipun, 2009. Psikologi Konseling. Malang: UMM Press.

Manuaba. 2012. Ilmu Kebidanan, Penyakit Kandungan dan $K B$. Jakarta : EGC

Mubarak. W. I. (2011). Promosi kesehatan. Jogyakarta : Graha ilmu.

Nurhayati, N. dan Muhammad, T., 2012. Serba -Serbi Kehamilan dan Perawatan Anak. Bandung: $\mathrm{Cv}$ Yrama Widya

Pratignyo, Tia. 2014. Yoga Ibu Hamil plus Postnatal Yoga. Jakarta: Pustaka Bunda.

Prawirohardjo, Sarwono. 2011. Ilmu Kebidanan. Edisi Empat. Jakarta 
:YayasanBina Pustaka Sarwono Prawirohardjo.

Rochjati, P. 2011. Skrining Antenatal Pada Ibu Hamil. Airlangga University Press, Edisi 2,43

Rusmita, E. 2015. Pengaruh Senam Hamil Yoga Terhadap Kesiapan Ibu Hamil Menghadapi Persalinan di RSIA Limijati Bandung. Jurnal Ilmu Keperawatan, 3(2), pp. 38-46

Syamsi, Ibnu. 2000. Pengambilan Keputusan Dan System Informasi. Jakarta: Bumi Aksara.

Sindhu, Pujiastuti. 2009. Hidup Sehat Dan Seimbang Dengan Yoga : Daily Practice. Bandung: Penerbit Qanita.

Sri Rumini, dkk. 1998. Psikologi Umum. Yogyakarta: Institut Keguruan dan ilmu Pendidikan.

Sugiyono. 2006. Metode Penelitian Kuantitatif Kualitatif dan $R \& D$. Bandung: Alfabeta.

Sugiyono. 2010. Metode Penelitian Pendidikan Pendekatan Kuantitatif, kualitatif, dan $R \& D$. Bandung: Alfabeta

Sulistyorini, C. I., \& dkk. 2010. Posyandu dan Desa Siaga Panduan untuk Bidan dan Kader. Yogyakarta: Nuha Medika

Sukarni, I dan Wahyu, P. 2013. Buku Ajar Keperawatan Maternitas. Yogyakarta: Nuha Medika
WHO. 2014. Maternal Mortality: World Health Organization.

WHO. 2007. Community health workers: What do we know about them? The state of the evidence on programmes, activities, costs and impact on health outcomes of using community health workers. Department of Human Resources for Health Geneva : Geneva.

WHO, UNICEF, UNFPA, and The World Bank Estimates. 2010. Trends in Maternal Mortality. Geneva.

Wiknjosastro, Hanifa. Ilmu Kebidanan. Jakarta: Yayasan Bina Pustaka Sarwono Prawirohardjo; 2009

Wulandari, P. E. 2011. Gambaran FaktorFaktor Yang Beresiko Tinggi. http://jurnalpenelitiankesehatan.com. Diakses tanggal 03 Juni 2020.

Zulkifli, 2003. Posyandu dan Kader Kesehatan. Pelaksanaan Program Deteksi Dini Tumbuh Kembang Balita di Posyandu. http://library.usu.ac.id. Diakses tanggal 03 Juni 2020. 